\title{
Una donación entre judíos segovianos, originalmente en hebreo, del año 1487
}

\author{
A donation between Segovian Jewish, originally written in \\ hebrew, year 1487
}

\author{
Bonifacio Bartolomé Herrero*
}

\section{RESUMEN}

En este trabajo se transcribe $y$ comenta un documento de donación redactado originalmente en hebreo en 1487 y cuyo contenido se ha conservado a través de su traducción al castellano en 1496. La importancia de este texto radica en que es el único testimonio conocido hasta el momento de un documento en hebreo redactado en el seno de la aljama judía de Segovia, una de las más importantes de la península ibérica en el último cuarto del siglo XV. Para situar el documento en su adecuado contexto se ofrece una visión general de la comunidad judía de Segovia durante el reinado de los Reyes Católicos y una breve biografía del receptor de la donación, el herrero judío

Yuçe Biton, convertido más tarde al cristianismo con el nombre de Alonso de

Palencia.

\section{PALABRAS CLAVE}

Siglo XV. Castilla. Segovia. Judíos. Judeoconvexos.

\section{ABSTRACT}

The present work transcribes and comments a document of donation originally written in Hebrew in 1487. The contents of the document have been kept thanks to its translation to the Spanish language in 1496. Its relevance lies on the fact that it is, so far, the only testimony in Hebrew language we have evidence on, written in the Jewish quarter in the town of Segovia, which was one of the most important Hebrew communities in the Iberian Peninsula in the last quarter of the $15^{\text {th }}$ century. In order to set the document in its context, it is offered a general perspective of the Hebrew community in Segovia during the Catholic Monarchs kingdom and a brief biography of the receiver of the donation, the Jewish blacksmith Yuçe Biton, who became a Christian afterwards under the name of Alonso de Palencia.

\section{KEY WORDS}

$15^{\text {th }}$ Century. Kingdom of Castile. Town of Segovia. Hebrew community. Converts (from Judaism).

\footnotetext{
* Doctor en Historia. Archivo de la Catedral de Segovia. Correo electrónico: bbartolome@ hotmail.com
} 


\section{LA ALJAMA JUDÍA DE SEGOVIA DURANTE EL REINADO DE LOS REYES CATÓLICOS}

Cuando los Reyes Católicos accedieron al trono en 1474, Segovia albergaba una de las comunidades judías más importantes de todo el reino. Durante las dos décadas de reinado de Enrique IV la política de tolerancia del monarca hacia los judíos había tenido una especial repercusión en Segovia, ciudad por la que el rey Enrique mostró durante toda su vida una especial preferencia. Como indica Eleazar Gutwirth, «el verdadero poder administrativo, político y económico de las aljamas parece haberse concentrado en Segovia. R. Joseph ibn Shem Tov, Jaco aben Núñez, Abraham Seneor, Meir Melamed eran vecinos, y también lo eran algunos de los más ricos financieros y arrendadores de la segunda mitad del siglo XV, cuya red de recaudadores y factores se extendía desde Oviedo y León hasta Utrera, Llerena y Jerez en el sur» ${ }^{1}$.

La integración en la aljama de Segovia de estos destacados miembros de la comunidad judía castellana no puede hacer olvidar que en realidad la población hebrea de la ciudad estaba formada mayoritariamente por artesanos. La documentación nos muestra a la mayor parte de ellos ligados a la industria textil, al trabajo con el metal, a la confección de ropajes y calzado, y a la joyería².

A fines del siglo XV la aljama segoviana mantenía fuertes tensiones en su seno a causa de las diferencias insalvables que existían entre los dirigentes de la comunidad y el resto de sus integrantes. Los primeros fueron denunciados por los segundos, y no sin razón, de adjudicar desigualmente el pago de las crecientes cargas fiscales impuestas por la corona. La actitud de Abraham Seneor, que controlaba los destinos de la aljama sin tolerar la más mínima oposición, también suscitó numerosas protestas.

Los testimonios de estos enfrentamientos son numerosos. En 1490 los reyes atendieron la queja de Abraham Alboer y ordenaron a su corregidor que proveyera lo necesario para que en el pago de los pechos y derramas contribuyeran todos los miembros de la aljama hebrea por igual ${ }^{3}$. Ese mismo año el judío segoviano Jacob Cachopo, procurador de las aljamas del reino, solicitó a los monarcas una carta de seguro para protegerse de los ataques que estaba recibiendo de Abraham Seneor y de otros judíos de la ciudad ${ }^{4}$.

Durante la segunda mitad de la década de los setenta la aljama hebrea de Segovia mantuvo la prosperidad y la estabilidad de la que había gozado a lo largo del reinado de Enrique IV, pero la modificación por los Reyes Católicos de su política hacia judíos y judeoconversos terminó por romper el difícil equilibrio que existía en la ciudad, abriendo un período de crisis que sólo se cerró tras la expulsión de 1492.

1 GUTWIRTH, E., «Elementos étnicos e históricos en las relaciones judeo-conversas en Segovia», Jews and Conversos. Studies in Society and the Inquisition, Jerusalén, 1985, p. 85.

2 RUIZ HERNANDO, J.A., El barrio de la aljama hebrea de la ciudad de Segovia, Segovia, 1980, p. 12.

3 Archivo General de Simancas (AGS), Registro general del sello, VIII, 1490, fol. 286.

4 AGS, Registro general del sello, X, 1490, fol. 251. 
En las cortes celebradas en Toledo en 1480 los monarcas ordenaron que los judíos fueran separados del resto de la población en barrios propios, renovando de este modo la disposición recogida en las leyes de Ayllón de 1412. En Segovia la fijación de los límites de la judería se llevó a efecto el 29 de octubre de 1481 bajo la supervisión del delegado regio Rodrigo Álvarez Maldonado, quien se vio obligado a moderar el excesivo celo mostrado por las autoridades concejiles al levantar alguna de las puertas que habían de cerrar el recinto 5 . Una vez establecido, el barrio judío se mantuvo sin modificaciones hasta la expulsión. Tras producirse ésta se derribaron los muros y las puertas que lo delimitaban, abriéndose de nuevo sus calles al resto de la ciudad.

Los monarcas aplicaron en Segovia la misma política hacia los judíos que mantuvieron en el resto del reino. La presión sobre esta comunidad, que se inició en las cortes de Toledo de 1480 y culminó una década después con el decreto de expulsión, buscaba en último término la unidad religiosa del reino mediante la conversión definitiva al cristianismo de los miembros de la comunidad hebrea. Sin embargo, los reyes no dejaron nunca de proteger de un modo particular a cualquiera de sus súbditos judíos de las agresiones que pudieran recibir en sus bienes y propiedades, ni de ampararlos frente a los ataques de los que fueran objeto.

A la vista de la política adoptada por la monarquía sobre los judíos, algunas instituciones segovianas comenzaron a hacer efectivas sus reivindicaciones sobre la comunidad judía. Pronto pudieron comprobar que los reyes no estaban dispuestos a tolerar ningún radicalismo que pudiera poner en peligro el nuevo orden que deseaban establecer, ni iban a permitir que aumentara la presión fiscal sobre una comunidad en la que ya recaía buena parte del esfuerzo financiero que sostenía la guerra contra el reino nazarí de Granada.

Durante esta etapa las autoridades concejiles segovianas mantuvieron una relación poco cordial con la comunidad judía. Más que sostener una beligerancia sistemática contra la aljama hebrea todo indica que trataron de aprovechar la coyuntura para presionar a los judíos, especialmente desde el ámbito fiscal. En 1488, por ejemplo, el concejo fue obligado por los monarcas a restituir a la aljama hebrea cierta ropa que le había tomado y se le advirtió de que en adelante no pidiera a ésta ropa, dinero o cualquier otra cosa para el corregidor, los alcaldes, alguaciles y sus criados ${ }^{6}$.

En Segovia la oposición religiosa y social a los judíos tuvo su centro en el monasterio dominico de Santa Cruz, cuyo prior, fray Tomás de Torquemada, fue nombrado inquisidor general en 1483. Poco tiempo después un miembro de la comunidad dominica, fray Francisco de la Peña, comenzó a hacerse notar por unas predicaciones públicas en las que predisponía abiertamente a la población contra los judíos con afirmaciones como la de que «sy non ponen fuego al monte que non podrían echar los lobos fuera». En marzo de 1485 los reyes ordenaron al bachiller

5 FITA, F., «La judería de Segovia. Documentos inéditos», Boletín de la Real Academia de la Historia, IX (1886), pp. 270-285.

6 AGS, Registro general del sello, XI, 1488, fol. 263. 
Alvar Fernández que impidiera al dominico seguir pronunciando sus incendiarios sermones ${ }^{7}$. No debió cesar el exaltado monje en sus propósitos, pues tan solo un mes después los monarcas encargaron al corregidor Ruy González que investigara de nuevo las predicaciones del dominico ${ }^{8}$.

La llegada de la inquisición a Segovia desató tensiones acumuladas desde décadas atrás en la ciudad. El rechazo popular hacia los judíos, que no encontraba cauce alguno de expresión por la actitud vigilante de la justicia regia, pudo derivarse ahora sin ninguna cortapisa hacia los judeoconversos. Las testificaciones recogidas en el proceso abierto contra algunos miembros de la influyente familia Arias Dávila resultan verdaderamente significativas a este respecto ${ }^{9}$. Pero en Segovia adjudicar la crispación existente a razones exclusivamente religiosas sería una errónea simplificación.

Desde los años finales del reinado de Enrique IV dos linajes, judeoconversos ambos por cierto, se disputaban el control político de la ciudad. Si en un primer momento la balanza se inclinó del lado de los Arias Dávila, finalmente sería Andrés de Cabrera, el futuro marqués de Moya, quien se convirtió en el verdadero dominador de la ciudad. En 1473, en uno de los episodios de la lucha por el poder entre ambas familias, Juan Pacheco, marqués de Villena y mentor de los Arias Dávila, intentó apoderarse del alcázar camuflando esta acción como un alboroto contra los conversos ${ }^{10}$. La lucha política, la rivalidad social y la tensión religiosa se mezclaban sin tapujos.

Las clientelas respectivas de los Arias y los Cabrera eran muy extensas y revelan lo intrincado de las relaciones sociales en la Segovia del momento. La familia Arias Dávila, por ejemplo, extendía su influencia a los dos grandes ámbitos de poder, el civil y el eclesiástico. Mientras Pedro Arias Dávila era uno de los regidores del concejo, su hermano Juan era el obispo de la diócesis. Las relaciones de esta familia se extendían a todos los grupos sociales. Como ya se ha visto, mantenían alianzas con alguno de los linajes más destacados del reino, como los $\mathrm{Pa}$ checo. En una práctica común en la época, los Arias Dávila establecieron alianzas matrimoniales con otros linajes conversos de la ciudad, como los de la Hoz. El origen judío de la familia Arias Dávila la llevó también a mantener lazos, obligadamente discretos, con sus parientes hebreos. Cuando Elvira González, la primera esposa de Diego Arias, acudió a velar a su hermana judía recién fallecida hubo de soportar el reproche de una tal Lucía González. Elvira respondió, como no podía ser de otro modo, "que era su hermana y su sangre abía ydo allis 11.

Esta compleja situación era la que se vivía en la ciudad de Segovia cuando, de un modo inesperado, los Reyes Católicos promulgaron el 31 de marzo de 1492 un

\footnotetext{
7 AGS, Registro general del sello, III, 1485, fol. 189.

8 AGS, Registro general del sello, IV, 1485, fol. 300.

9 CARRETE PARRONDO, C., Fontes Iudaeorum Regni Castellae. III. Proceso inquisitorial contra los Arias Dávila segovianos: un enfrentamiento social entre judíos y conversos, Salamanca, 1986.

10 PALENCIA, A. de, Crónica de Enrique IV, ed. de A. Paz y Meliá, Madrid, 1975, década II, libro VIII, capítulo I; vol. II, pp. 93-94.

11 CARRETE PARRONDO, C., Fontes..., p. 20, n 5.
} 
decreto por el que señalaban a los judíos un plazo de cuatro meses para convertirse al cristianismo o abandonar el reino. Como nos relata un anónimo testigo, en la ciudad de Segovia este decreto fue pregonado públicamente un mes después de su redacción en Granada:

«Martes primero dia del mes de mayo, dia de los bienaventurados apostolos San Philipe e Santiago, anno de Nuestro Sennor y Salvador Ihesu Christo de mill e quatrocientos e noventa e dos annos, reynantes en Castilla los muy serenissimos don Fernando e donna Ysabel reyes de Castilla e de Granada, fue publicado en Segovia e en toda Castilla de mandado de sus altesas como vacassen de sus reynos todos los judíos que estavan en suys reynos. Dioles seguro con que saliesen dentro de tres messes de sus reynos e que no llevassen consigo oro ni plata ni moneda amoneda(da) ni armas ni otras cosas vedadas salvo mercadorías etc. Publicose el dia susodicho en el monasterio de Sancta Cruz desta çibdad estando ay todo el pueblo desta dicha çibdad, que fueron y concurrieron allí con muy devota e notable proçessión. Demos a Dios Nuestro Sennor infinytas graçias que permitio ser echados los infieles de nuestros reynos ${ }^{12}$.

Tras la publicación del decreto, los judíos segovianos comenzaron a preparar su salida de la ciudad y procedieron a la liquidación de sus bienes. La primera operación conocida es la realizada por David Collarano y su hijo Jacob, que el 4 de mayo traspasaron a Catalina Ruiz el censo de la casa en que vivían por cuatro mil maravedís ${ }^{13}$. Desde este momento la sucesión de transacciones fue continua. La última de la que tengo constancia es la llevada a cabo el 16 de julio por Frayme de Vidas, quien traspasó el censo de la vivienda en que residía a Luis de Villiça ${ }^{14}$.

Antes de que finalizara el plazo fijado por los Reyes Católicos para la expulsión se produjo la conversión de Abraham Seneor, quizá la más significada de todas las que se efectuaron en aquel momento. De la relevancia de este acontecimiento da buena fe el hecho de que el bautismo, llevado a efecto en el monasterio cacereño de Guadalupe el 15 de junio de 1492, fue apadrinado por los propios monarcas. No parece en todo caso que esta ceremonia, de evidente dimensión propagandística, contribuyera a evitar la salida masiva de judíos del reino.

Desgraciadamente resulta imposible constatar cuántos fueron los judíos segovianos que decidieron abandonar la ciudad y que número de ellos se convirtió en aquellos momentos al cristianismo. En realidad ni siquiera se sabe con certeza cual era la población hebrea de Segovia a fines del siglo XV. El único dato conocido a este respecto lo proporciona un censo de conversos realizado en 1510 que refleja la existencia en la ciudad de setecientos ochenta y ocho judeoconversos. Éstos se agrupaban en doscientas nueve familias que permanecían mayoritariamente en sus asentamientos tradicionales de las parroquias de San Andrés y San Miguel ${ }^{15}$.

12 Archivo de la Catedral de Segovia (ACS), B-247, fol. 53 v.

13 ACS, F-75.

14 Archivo Histórico Provincial de Segovia, Delegación de Hacienda, carpeta 2, exp. 28. El documento no recoge la cantidad que recibió Frayme de Vidas por el traspaso del censo.

15 BATAILLON, M., «Les nouveaux chrétiens de Ségovie en 1510», Estudios Segovianos, X (1958), pp. 393-428. ASENJO GONZÁLEZ, M., Segovia. La ciudad y su tierra a fines del medievo, Segovia, 1986, pp. 335-337. 
La expulsión de los judíos, completada con la de los musulmanes una década después, logró, al menos sobre el papel, la unidad religiosa del reino pero provocó a su vez numerosos problemas. Algunos de los judíos que abandonaron el reino decidieron finalmente bautizarse y volver a las ciudades donde residían. Aunque los reyes les garantizaron la recuperación de las propiedades y derechos que habían vendido a su salida, el acceso a los mismos resultó, en algunos casos, muy problemático.

El cobro por parte de los judeoconversos de los préstamos que todavía no habían sido liquidados resultó verdaderamente conflictivo. La mayor parte de estos préstamos habían sido traspasados a terceros y los cristianos que debían devolverlos alegaron en muchos casos la existencia de usura para evitar su pago ${ }^{16}$. La recuperación por los judíos conversos de los bienes inmuebles vendidos a su salida del reino resultó, por lo general, menos problemática. Los reyes habían dispuesto que los compradores devolvieran las casas y los otros bienes raíces a sus antiguos propietarios a cambio de la cantidad que habían pagado por ellos y de lo que hubiesen invertido en su mejora.

En Segovia el primer retorno conocido es el del financiero Jacob Galfón, que el 20 de noviembre de 1492 fue autorizado por los reyes para volver desde Portugal con su familia y criados. Una vez en Segovia, Jacob, que adoptó el nombre de Pedro Suárez de la Concha, hubo de hacer frente a diversas denuncias en su contra por actuaciones llevadas a cabo en los tiempos en que todavía era judío y se vio obligado a promover varias acciones judiciales para recuperar los numerosos préstamos cuyo cobro todavía tenía pendiente ${ }^{17}$.

\section{LA DONACIÓN DE 1487}

El año 1487 la judía segoviana Jamila y su marido Hezra Biton donaron a su hijo Yuçe Biton una casa con su corral y un solar en la judería. Aunque el original de esta donación se ha perdido, su contenido se conserva en una traducción al castellano realizada en $1496^{18}$.

Esta traducción está formada por dos pliegos de papel que conforman cuatro hojas de $305 \times 215 \mathrm{~mm}$. El texto aparece escrito en las cinco primeras páginas, encontrándose las tres últimas en blanco ${ }^{19}$. En la última de las hojas se aprecia la

16 MORENO KOCH, Y., «Las deudas de los judíos de Segovia después de la expulsión», El Olivo, XVII, 37 (1993), pp. 83-89.

17 MORENO KOCH, Y., «De la diáspora hacia Sefarad. ¿La primera carta de regreso de un judío convertido?», Michael, XI (1989), pp. 257-265.

18 ACS, D-1293. El documento se encuentra cosido junto a otros originales en un volumen que recoge documentos pertenecientes a los capellanes del número.

19 En el verso del cuarto folio pueden leerse diversas anotaciones: «Carta de la venta que hizo el padre de Alonso de Palençia al dicho su fijo de la casa que el tiene»; otra letra, "Vease que es curioso»; otra letra, «Estas cassas se dieron a censo y los reditos cobra el Numero para la fundación de Pedro Alonso y despues se trocaron por otras a San Esteban con que este instrumento pertenece a el que tomo estas cassas»; otra letra, «San Miguel»; y otra letra, «San Miguel». 
existencia de una filigrana consistente en una mano de cuyo dedo anular sale una estrella de seis puntas, marca que aparece con gran frecuencia en los papeles de la época.

La transmisión documental de la donación, único testimonio conocido de un documento redactado en hebreo en el seno de la aljama judía segoviana, transcurrió durante nueve años, entre 1487 y 1496.

El 21 de octubre de 1487 se produjo la donación de la casa con su corral y de los cuatro codos de suelo, propiedades que tenían un valor conjunto de cuarenta mil maravedís. Como se recoge en la propia donación, ésta se realizó para compensar al mencionado Yuçe del pago de ciertas deudas correspondientes a sus padres y para resarcirle del dinero que había entregado a sus hermanas «para casamiento" y a su familia "en otras muchas neçesydades".

Seis meses más tarde, el 2 de marzo de 1488, se realizó un traslado del texto de la donación, pero no desde el documento original sino desde la copia conservada en los registros del fallecido Rabí Abraham, el escribano que lo había redactado. En el propio documento se indica que esta copia se efectuó «por mandamiento de justicia", y parece que la misma fue presentada en juicio. Es posible, por tanto, que hubiera surgido algún conflicto en torno a la donación o que se hiciera necesaria la obtención de una copia por pérdida del documento original o por cualquier otra razón.

Por último, el 28 de mayo de 1496 Yuçe, convertido al cristianismo con el nombre de Alonso de Palencia, presentó ante el alcalde segoviano Diego de Ocaña el mencionado traslado, contenido en "una escriptura escripta en pargamino de cuero de letra judiega», con objeto de que fuera traducido al castellano. De la traducción se encargaron los judíos conversos maestre Hernando y Alvar Núñez, que habían estado presentes en el traslado de 1488, mientras que el escribano público Juan Rodríguez puso por escrito la misma ${ }^{20}$.

El 12 de octubre del año 1500 Alonso de Palencia vendió su casa en la antigua judería y una tenería situada extramuros al beneficiado catedralicio Diego de Castro, que actuaba como testamentario del racionero Pedro Alonso. A continuación el nuevo propietario estableció con Alonso de Palencia un censo enfiteútico sobre ambos inmuebles por una cantidad anual de mil maravedís ${ }^{21}$.

No conocemos la razón última que llevó a Alonso de Palencia a renunciar a la propiedad de la casa que había recibido de sus padres y a convertirse en censatario de la misma, pero son varias las causas que podrían haber motivado esta decisión. Renunciando a la propiedad de la vivienda pero garantizándose el derecho a residir en ella de por vida a cambio de un censo anual, Alonso se protegía contra

20 Resulta evidente que el escribano encontró ciertas dificultades al poner por escrito palabras y fórmulas que le eran claramente ajenas. Como ejemplo baste mencionar el hecho de que a lo largo del documento cita al receptor de la donación como «Yuçe», «Yufe», «Çe» o «Yuçafe».

21 La noticia de este documento, realizado en Segovia ante el notario Hernando de Villafañe, está recogida en el documento citado en la nota 26. 
cualquier futura contingencia. Esta operación, de hecho, hacía muy difícil su hipotética expulsión de la vivienda. También cabe considerar la circunstancia de que el herrero necesitase dinero en efectivo y decidiese vender la casa, pero reservándose la residencia en la misma.

La casa que vendió Alonso de Palencia era sin duda la que había recibido de sus padres, pues los linderos que de la misma se mencionan el año 1500 se identifican plenamente con los señalados en $1487^{22}$. La tenería, situada extramuros junto a la puerta de San Andrés y al río Clamores, se encontraba al lado de otra instalación similar "en que bivie Juan de Paris», impresor alemán de cuyo taller salió el primer libro realizado en España ${ }^{23}$.

El racionero Pedro Alonso había estipulado en su testamento, fechado el 22 de febrero de 1500, la celebración en la catedral de Segovia de un aniversario por su alma y de un responso diario sobre su tumba ${ }^{24}$. Don Pedro debió morir poco después de redactado el documento, en todo caso antes de octubre, momento en el que Diego de Castro compró la casa y la tenería a Alonso de Palencia. En abril de 1501 los testamentarios de Pedro Alonso, el mencionado Diego de Castro y el canónigo Alonso de San Andrés, acordaron con los capellanes del número la dotación del aniversario y los mencionados responsos con mil cien maravedís anuales, aunque la operación no se cerró hasta cinco años después ${ }^{25}$.

En efecto, en 1506 Diego de Castro cedió definitivamente a los capellanes catedralicios la propiedad de una casa y dos tenerías gravadas con sendos censos enfiteúticos que proporcionaban una renta anual de mil ciento treinta y seis maravedís, treinta y seis más de los estipulados inicialmente ${ }^{26}$. Mil de ellos correspondían a la casa situada en la parroquia de San Miguel y a la tenería establecida junto al río Clamores y eran pagados por Alonso de Palencia. Los ciento treinta y seis maravedís restantes correspondían a otra tenería que lindaba con la citada anteriormente y eran abonados por el «agujetero» Francisco de Salamanca ${ }^{27}$.

La casa de la antigua judería permaneció en manos de los capellanes del número hasta que, en fecha desconocida, éstos entregaron su propiedad a Juan Izquierdo a cambio de otra vivienda que éste poseía en la parroquia de San Este-

22 En 1487 la casa tenía por vecinos a Yuda Lozano y a Jacob Galfon, «e de la çaguera una çerca de las monjas del monesterio de Santa Clara, e de la otra parte, donde esta la puerta abierta, la calle publica la qual calle sale all Almuzara». En 1500 se indica «que han por linderos las dichas casas, que son a la dicha collaçion de Sant Miguell en las quales bive el dicho Alfonso de Palençia, de la una parte casas de Hernand Gomes e por la otra parte casas de Hernando de la Torre e por las espaldas çerca de las monjas de Sant Antonio e por delante la calle publica real que va al Almuzara». 2004

${ }^{23}$ Sobre este tipógrafo y su obra, VV.AA. Juan Párix. Primer impresor en España, Salamanca,

${ }^{24}$ La noticia de este testamento, realizado en Segovia ante el notario Hernando de Villafañe, está recogida en el documento citado en la nota 26.

25 (1501, abril, 5, Segovia). ACS, D-1364.

26 (1506, agosto, 22, Segovia). ACS, D-1364. RUIZ HERNANDO, J.A., Historia del urbanismo en la ciudad de Segovia del siglo XII al XIX, Segovia, 1982, II, p. 208, $\mathrm{n}^{\circ} 121$, donde figura el documento con una data errónea.

27 Diego de Castro había comprado la tenería a Francisco de Salamanca el 18 de junio de 1505, como se recoge en el documento citado en la nota 26. 
ban $^{28}$. En este punto, y con el citado Juan Izquierdo como propietario, se pierden las noticias del inmueble recibido por Yuçe Biton en 1487.

\section{YUÇE BITON / ALONSO DE PALENCIA (FL.1478-1519)}

Yuçe Biton era un herrero judío, un miembro anónimo de la comunidad hebrea segoviana que se encontraba ciertamente alejado del entorno de los grandes magnates como Seneor o Melamed. A pesar de ello, tenemos la fortuna de que la documentación de la época haya recogido su trayectoria vital durante nada menos que cuatro décadas. Esta circunstancia, ciertamente excepcional, nos va a permitir observar, aunque con más limitaciones de las que desearíamos, la actividad y las actitudes de un artesano judío en las décadas anteriores y posteriores a la expulsión decretada por los Reyes Católicos.

La primera mención conocida de Yuçe se encuentra en diciembre de 1478 en un registro de la mayordomía de fábrica de la catedral de Segovia que recoge el pago efectuado al herrero por la realización de tres badajos, seis clavos y dos grapas ${ }^{29}$. Desde ese momento el artesano aparecerá con regularidad en los registros capitulares.

En 1487, nueve años después, Yuçe recibió de sus padres la casa y el solar mencionados más arriba. En esos momentos la familia del herrero estaba compuesta por sus padres, Hezra Biton y Jamila, y por varias hermanas casadas. La documentación de la época recoge la existencia en la comunidad judía de Segovia de otras dos personas con el apellido Biton, cuyo parentesco con Yuçe se nos escapa. El primero de ellos es Rabí Salomón Biton, diputado de la aljama, que en 1481 actuó como uno de los representantes de la comunidad hebrea en el acto de delimitación de la judería ${ }^{30}$. El segundo es Hiyan Biton, que figura aportando quinientos maravedís en el préstamo solicitado a la aljama segoviana por los Reyes Católicos en 1483 para atender los gastos ocasionados por la guerra con Granada ${ }^{31}$.

La cuantía de la donación recibida por Yuçe, valorada como se ha visto en cuarenta mil maravedís, permite suponer que sus padres gozaban de una posición económica muy desahogada. La misma de la que en realidad debía disfrutar el propio artesano, que había podido ofrecer ayuda a sus padres y hermanas cuando lo necesitaron y aparece en esos momentos como el referente financiero de su propia familia.

28 No se conserva el documento de trueque, pero diversas anotaciones realizadas en los documentos relacionados con la casa de la judería informan del mismo: «Estas cassas se dieron a censo y los reditos cobra el Numero para la fundación de Pedro Alonso y despues se trocaron por otras a San Esteban con que este instrumento pertenece a el que tomo estas cassas»; "Trocose por lo de Juan Izquierdo»; "Trocose este çense por el de Juan Ysquierdo».

29 LÓPEZ DÍEZ, M., «Judíos y mudéjares en la Catedral de Segovia (1458-1502)», Espacio, Tiempo y Forma. Serie III, $H^{a}$ Medieval, 18 (2005), p. 176.

30 FITA, F., La judería..., p. 270.

31 LADERO QUESADA, M.A., «Un préstamo de los judíos de Segovia y Ávila para la guerra de Granada, en el año 1483», Sefarad, XXXV (1975), p. 154. Hiyan Biton aportó, junto a Mosé Alfarin, la cantidad más baja de los treinta y siete participantes en el préstamo. 
El 20 de marzo de 1492 Yuçe Biton deja de figurar en los registros catedrali$\operatorname{cios}^{32}$. Lo significativo de esta fecha mueve a pensar que la circunstancia señalada fue una consecuencia directa del decreto de expulsión. Durante los dos años siguientes, hasta agosto de 1494, la existencia de Yuçe permanece en la sombra.

Aunque como ya se ha indicado no existe ninguna referencia sobre la actividad del herrero entre marzo de 1492 y agosto de 1494, parece razonable pensar que decidió abandonar la ciudad con el grueso de la comunidad hebrea. En efecto, resulta muy llamativo que durante ese período su nombre desaparezca completamente de los registros de la catedral, una institución para la que trabajaba al menos desde 1478 y con la que, tras reanudar su relación, volvería a colaborar durante más de dos décadas.

Cuando el herrero judío reaparece en 1494 lo hace bajo el nombre de Alonso de Palencia ${ }^{33}$. Resulta evidente por lo tanto que en ese intermedio de algo más de dos años se había convertido al cristianismo y había recibido el bautismo. Sobre las condiciones de su hipotética vuelta a la ciudad nada se puede decir, pues no se ha conservado ninguna autorización de regreso a su nombre ${ }^{34}$.

El 28 de mayo de 1496 Alonso de Palencia, identificado como vecino de Segovia, solicitó, «para guarda de su derecho», la convalidación del título de propiedad de la casa que había recibido de sus padres. Como se ha señalado más arriba, cuatro años después el herrero vendió el inmueble a Diego de Castro.

Un censo de conversos realizado en Segovia en 1510 recoge la presencia en la parroquia de San Miguel de «Alonso de Palencia, ferrero, e Catalina Alonso, su muger. Tienen dos fijos en casa, Diego e Fernando, de hedad diez y ocho y diez y siete años» ${ }^{35}$. Aunque se desconoce el momento en el que Alonso contrajo matrimonio, las edades de sus hijos permiten suponer que pudo haberse casado con Catalina hacia 1492. A comienzos del siglo XVI la familia residía en la casa que Alonso había recibido en donación en 1487 y de la que en ese momento era censatario.

La última noticia conocida de Alonso de Palencia se encuentra en 1519, de nuevo en los registros catedralicios, cuarenta y un años después de que apareciera en los mismos por primera vez ${ }^{36}$.

La discreta trayectoria vital de Yuçe Biton / Alonso de Palencia permite acercarse a la aljama judía de Segovia en unos momentos, los anteriores y los posteriores a la expulsión, que marcaron la existencia de esta comunidad hebrea de un modo definitivo. Siguiendo los pasos de Yuçe nos adentramos en una de las dos realidades en que quedó inevitablemente desgarrada la aljama, en este caso en la de aquellos que se convirtieron al cristianismo y permanecieron en la ciudad. Como hemos podido comprobar, para este artesano la decisión de renunciar a su

32 LÓPEZ DÍEZ, M., Judíos..., p. 176, nota 18.

${ }^{33}$ El 3 de agosto de 1494 Yuçe, ya como Alonso de Palencia, aparece cobrando diez maravedís por dos pernos para las ventanas del cabildo, LÓPEZ DíEZ, M., Judíos..., p. 176, nota 18.

${ }_{34}$ El Registro General del Sello no conserva ningún seguro expedido en favor de Yuçe Biton.

35 BATAILLON, M., Les nouveaux..., p. 408 ( $\left.n^{\circ} 52\right)$.

36 LÓPEZ DÍEZ, M., Judíos..., p. 176, nota 18. 
nombre y a las creencias recibidas de sus mayores no resultó fácil de tomar ni de inmediata ejecución. Quizá él se encontrara entre los más afortunados pues, al menos a nuestros ojos, contó con dos firmes bases sobre las que cimentar su nueva andadura, un hogar propio, donado en hebreo y vendido en castellano, y un oficio noble y antiguo como la humanidad misma, ejercido jornada tras jornada frente al yunque y a la fragua, que le permitió unir de un modo coherente su pasado y su presente.

\section{APÉNDICE DOCUMENTAL}

1496, mayo, 28. Segovia.

Diego de Ocaña, alcalde en Segovia, autoriza a petición del judío converso Alonso de Palencia la traducción al castellano de un traslado en hebreo (1488, marzo, 2, Segovia) de otro documento en hebreo (1487, octubre, 21, Segovia) por el que doña Jamila y su marido Hezra Biton donaban a su hijo Yuçe Biton (Alonso de Palencia) una casa, un corral y cuatro codos de suelo en la judería de Segovia valorados en cuarenta mil maravedís.

Archivo de la Catedral de Segovia, D-1293. Original. Papel, cuatro hojas, $305 \times 215 \mathrm{~mm}$.

Archivo de la Catedral de Segovia, F-79. Copia incompleta (1775, enero, 12, Segovia).

RUIZ HERNANDO, José Antonio, El barrio de la aljama hebrea de la ciudad de Segovia, Segovia, 1980, pp. 43-45. (Editado parcialmente).

(1 r.) En la noble çibdad de Segovia, veynte e ocho dias del mes de mayo anno del naçimiento de Nuestro Salvador Ihesu Christo de mill e quatrocientos e noventa e seys annos.

Estando antel bachiller Diego de Ocanna, allcalde en la dicha çibdad e su tierra por el honrrado cavallero Diego Ruys de Montalvo corregidor en la dicha çibdad e su tierra por nuestros sennores el rey e la reyna, e en presençia de mi Juan Rodrigues, escribano publico en la dicha çibdad e su tierra por el rey e la reyna nuestros sennores, e ante los testigos de yuso escriptos, pareçio presente Alonso de Palençia, vecino de la dicha çibdad, e presento antel dicho allcalde una escriptura escripta en pargamino de cuero de letra judiega. E asy presentada dixo que pedia e pydio al dicho allcalde que la mandase tornar en publica forma de letra judiega en letra christianyega e ge la mandase dar synada para guarda de su derecho. E el dicho allcalde dixo que lo oya.

E luego el dicho alcallde tomo e reçibio juramento de maestre Hernando e de Alvar Nunnes, convertidos vecinos de la dicha çibdad que presentes estavan, sobre la sennal de la crus en que pusyeron sus manos derechas corporalmente, que bien e leal e verdaderamente syn arte e syn enganno tornarian la dicha escriptura 
de letra judiega en letra christiana punto por punto e que no acreçentaryan ni menguarian en ella cosa alguna mas de lo que en ella se contiene. E los dichos maestre Hernando e Alvar Nunnes asy lo juraron, e que sy lo asy hizyesen que Dios todopoderoso les ayudase en este mundo a los cuerpos e en el otro a las animas donde mas avian de durar, e sy el contrario hizyesen quel ge lo demandase mal e catadamente (?) como aquellos que a sabiendas se perjuran e juran su santo nonbre en vano. Sobre lo qual el dicho allcalde les echo la confusyon del juramento e en respondiendo a ella cada uno dellos por sy dixo sy juro e amen. Testigos que fueron presentes a lo que dicho es Garcia Barroso e Hernando, criados del dicho allcalde.

E luego los dichos maestre Hernando e Alvar Nunnes dixeron que so cargo del juramento que fecho avyan, que lo que se contiene en la dicha escriptura de letra judiega en letra christiana es esto que se sygue:

En domingo quatro dias del mes de malresvan (sic) anno de çinco mill y dozyentos e quarenta e ocho naçimiento del mundo, que se contaron veynte e un dias del mes de otubre del anno de mill e quatrocientos e ochenta e syete annos a la quenta de los cristianos.

Tomaron recabdo conplido dende oy dende agora donna Jamila, muger de don Hezra Biton, con licençya del dicho su marido, quel dicho su marido le dio liçençia conplida por virtud del dicho recabdo para se obligar a lo que delante se sygue en todo y por todo, y el dicho don Hezra Biton su marido con ella, amos a dos vecinos en Segovia, e por virtud del dicho recabdo que tomaron, dixeron:

Que por quanto ellos y cada uno dellos tenian e an reçebido asaz buenos deudos e servicios de don Yuçe Biton, su hijo dellos vecino tanbien en Segovia, e a pagado por ellos asas muchas deudas, e / $(1 \mathrm{v}$.) e ( $\mathrm{sic}$ ) les a dado asas maravedis para casamiento de sus hijas, e a conplido con ellos en otras muchas neçesydades que an tenido, que para satisfaçion de los dichos cargos que asy les a fecho y faze:

Que otorgavan y otorgaron e quisyeron por propia su voluntad e saber çierto syn memoria de fuerça alguna, con coraçon conplido y saber reposado e anima voluntariosa e saber conplido de buen ojo e cuerpo sano, dieron al dicho don Yufe en donaçión quatro codos de suelo de su hazyenda, e a buelta dellos le dieron en donaçión conplida unas casas e corral que los dichos don Hezra e donna Jamila an e tienen en la juderia desta dicha çibdad de Segovia, que an por linderos de la una parte casas de don Yuda Loçano vecino tanbien en Segovia, e de la otra parte casas e corral que solian ser de don Jacob Yruab (?) e aora dis que son casas del honrrado don Jaco Galfon vecino tanbien en Segovia, e de la çaguera una çerca de las monjas del monesterio de Santa Clara, e de la otra parte, donde esta la puerta abierta, la calle publica la qual calle sale all Almuzara.

La qual dicha casa e corral asy deslindada dieron los dichos don Zezra e donna Jamila su muger al dicho don Çe su hijo en donaçion conplida segund dicho es, con todos sus provechos e fueros e salidas e entradas e puertas e ventanas e resquiçios e mahaques (?) e sus escaleras e paredes e sus fiagacaçiones (?) e corrimiento de aguas e otros serviçios, todo desde fondon de la tierra fasta lo alto del çielo. 
Todo lo dicho dieron los (sic) don Hezra e donna Jamila su muger al dicho don Yuçafe su hijo en donaçion conplida, donaçion de syenpre, donaçion donaçion (sic) publica, donaçion conplida e verdadera e firme segund ley e segund derecho, que no ay en ella revocaçion ni arrepentimiento e que no se tornara della ni se mudara della para syenpre jamas, donaçion de bivo, e de oy e dende agora e para syenpre.

E dende agora vaya el dicho don Yuçafe gozador de la dicha donaçion e tome posysyon desta donaçion, posysyon conplida para syenpre, el y los que del vinieren ereden y hagan heredar, edefiçien, derruequen, e enpennen, e de en donaçion e venda e haga de la dicha casa e corral como quysyeren e por bien tovieren, por quanto con buen ojo e con toda lengua de linpiesa dieron los dichos dadores al dicho gozador esta donaçion, como dicho es.

E no dexaron los dichos dadores en esta donaçion para sy ni para ningund honbre de todos los que dellos vinieren ningund dexamiento de derecho para syenpre jamas. E afirmaronse e hizyeron estar e poseher los dichos dadores esta donaçion en poder del dicho gozador della e en poder de todos los que del vinieren, afirmaçion conplida e estançia entera dende oy e dende agora e para syenpre, linpya / (2 r.) e (...) guarda de todas maneras de contrallamientos que en el mundo oviere. E dende agora alçaron los dichos dadores de sobre esta donaçion a sy mismos e su poder e su gozamiento, e sustançia e poder e gozamiento de todos los que dellos vinieren, alçamiento conplido para syenpre jamas.

E sy viniere de qualquiera de quatro partes del mundo hijo o hija, o hermano o hermana, çercano o alexado, heredero partiçionero judio o cristiano que razonare, contrallare, rebolviere alguna razon o algund contrallamiento o rebolvimiento sobre esta donaçion o sobre parte della, que sus palabras e sus hablas sean baldadas e contadas como un tiesto quebrado que no ay en el sustançia e como un acuerdo que no ay en el voluntad sobre los dichos dadores para esparzyr, enpuxar, alçar de sobre esta donaçion qualesquier contralladores o razonadores ni demandadores desde el dia que se tomase el dicho contrallamiento o rebolvimiento fasta tres dias syguientes, por manera que queden las dichas casas e corral de la manera que dicha es en poder del dicho don Yuçafe e de los que del vinieren, por quanto dende agora los dichos dadores e cada uno dellos se alçaren a sy mismos alçamiento conplido de la posysyon e tenençia de la dicha casa e corral e la davan e dieron al dicho don Yuçafe como dicho es en cada e qualquyer solenidad de derecho que posysyon pueda aver o aya en el mundo.

E recybieron sobre sy los dichos dadores e cada uno dellos por virtud del dicho recabdo e entraron e se hyzyeron deudores obligados e reçebidores e fyadores, uno por otro, rico por pobre, bivo por muerto, el que fuere fallado por el que no fuere hallado, para alçar de sobre esta donaçion qualesquier contrallador o razonador o demandador que razonare o contrallare o rebolviere qualesquier rrazon o contrallamiento o rebolvimiento sobre esta donaçion o sobre parte della desde el dia que començare el tal rebolvimiento fasta tres dias syguientes, como dicho es.

E que pagaran a ellos o a qualquyera dellos quarenta mill maravedis de la moneda usual agora en el reyno de Castilla, que justamente pueden aver reçebido los 
dichos dadores del dicho don Yuçafe en las cosas que fasta oy dia dixeron los dichos dadores que le son en cargo al dicho don Yuçafe su fijo de los dichos gastos que por ellos e con ellos a fecho. E que pagados los dichos quarenta mill maravedis o non, que todavia faran sana la dicha donaçion en poder del dicho don Yuçafe e de los quel vinyeren.

Y que para pagar los dichos quarenta mill maravedis, sy no hyzieren sana la dicha casa o non alçaren qualesquyer contrallador y razonador y demandador y rebolvedor de sobre esta donaçion al dicho tienpo, segund dicho es, obligaron a sy mismos los dichos / $(2 \mathrm{v}$.) dadores para prisyon de cuerpo y que pagaran el doblo de los dichos quarenta mill maravedis a qualesquyera que sacare este recabdo de donaçion con qualesquyer cofecho y danno y gasto que se rebolviere al dicho don Yuçafe e a los que del vinieren por cabsa de la dicha cobrança de los dichos quarenta mill maravedis, segund dicho es.

$Y$ fieldad conplida dieron los dichos dadores e cada uno dellos a qualquyera que sacare este recabdo en todos los casos deste recabdo de donaçión en la cobrança de los dichos quarenta mill maravedis como a dos testigos buenos (?) o syn que le obliguen a haser ningund juramento, ni aun descomunion çerradamente.

E juraron los dichos dadores e cada uno dellos juramento fuerte, tocando la mano e mentando el nonbre de Dios segund ley e segund derecho, syn ninguna cabsa nin razon de arteria ni trafago, nin syn ninguna parte de puerta de suelta (?), nin de arrepentimiento, segund el seso de Dios e del seso de los que juran en verdad, e con baldamiento de qualesquyer maneras de saberes del mundo publicas e ocultas, de prinçipyo fasta fin, que non tenian vendida nin enpennada nin dada en donaçion nin trocada la dicha casa e corral, nin la venderan ni enpennaran nin daran nin trocaran ni canbiaran en ningund tienpo a ningund honbre e en ninguna razon, salvo que quede la dicha donaçion firmada e confirmada en poder del dicho don Yuçafe y en poder de todos los que del vinieren, como dicho es.

E que para lo non conplir no se aprovecharan los dichos dadores nin alguno dellos de ninguna carta de rey e de reyna, Dios los guarde, nin de ninguna ley nin fuero de nuestra ley nin fuera de nuestra ley, ni de ninguna razon en el mundo en contrario de todo lo escripto en este recabdo de donaçyon, en juyzyo nin fuera de juyzyo, ellos ni otros por ellos.

E que se pueda haser este recabdo de donaçion desde una ves hasta çiento con consejo de letrados judios o christyanos fasta que sea firme e fuerte en poder de quien le sacare y aun depues que sea pareçida en juyzyo.

E ansy dixeron los dichos dadores: esta donaçion escrevilda o fazelda espcrevir en la plaça publicamente e firmalda en los canpos, que no sea como donaçion encubierta nin como donaçion del que esta doliente en cama, salvo descubierta y publica, y donaçion de sano y como donaçion fuerte en todas maneras de fuerças e firmezas que en el mundo ay, segund que la hordenaron los sabios, para todos los recabdos e donaciones. Todo lo dicho con obligaçion conplida sobre los dichos dadores e sobre cada uno dellos e sobre todos sus herederos e sobre / (3 $r$.) todas sus hazyendas rayzes e muebles que tienen o toviesen, segund hor- 
denança de los sabios, que no sea commo acofirmiento (?) ni con denotes de recados salvo derecho natural.

E reserbimos recado de los dichos don Hezra e donna Jamilla, su muger, sobre todo lo escripto sobrellos arriba, recado conplido como cosa que es bueno para tomar recaudo con el. E fue conplido todo esto en el dia e mes e anno arriba contenido (?) en Segovia.

Va sobre rapado do dize de la, e todo es bueno e firme e vala, esta ni esta firma firmado ube, e yo Ariel.

Dize mas avaxo de la firma: $E$ nosotros los firmados abaxo damos fe e testigo de Rabi Abrahan Zaad (?), escribano ya defunto, de su letra de lo Abi (sic) Abrahan, e firmado en el dicho registro don Yuçafe (...)diel el dicho testigo arriba firmado en fin del recaudo.

E por quanto el dicho Rabi Abran es partido desta vida presente sacamos este dicho recabdo por mandamiento de justicia del dicho su registro e firmamos aquy nuestros nonbres en su lugar, en martes dos dias del mes de adar anno de çinco mill y dozyentos quarenta nueve annos a la quenta del naçimyento del mundo, que se cuenta el dicho mes el mes de março de mill e quatrocientos e ochenta y ocho annos a la quenta de los christyanos en Segovia. Es firme e valedero. Los testigos que aqui estavan firmados son estos: Salamon, fijo de Samuel de Cuellar ya defunto, e Mayr, fijo de Yuçe de Vidas.

Esto dizie mas en la dicha escriptura: Que fue averiguado este recaudo en nuestra presencia en juysio (?) segund de vos y fue aclarado a nosotros. Que la firma destos testigos de arriba firmados son ellos, por donde la (tachado)vamos e la confirmamos e posymos nuestras firmas aqui en juyzyo, e es confirmado con esto la dicha escriptura. Testigos que vieron firmar a los testigos que arriba estan firmados, son e estan firmados aqui, se dizyen por nonbre Yuçe Atrache, Ysaque Galfon, maestre Hernando, Alvar Nunnes.

E asy presentada la dicha escriptura e tornada en publica forma como dicho es, el dicho allcalde dixo que lo oya e que mandava e mando a mi el dicho escribano que lo diese sygnado de mi sygno al dicho Alonso de Palençia para guarda de su derecho. Testigos que fueron presentes a lo que dicho es, los dichos Garcia Barroso e Hernando de Tapia, vecinos de la dicha çibdad.

E yo el dicho Juan Rodrigues, escribano publico suso dicho en la dicha çibdad e su tierra, fuy presente a esto que dicho es con los dichos testigos, e a pedimiento del dicho Alfonso de Palençia lo fis escrivyr e fis ay este mio syg(signo)no en testimonio. Juan Rodrigues. 